\title{
Household-level double burden of malnutrition in Ethiopia: a comparison of Addis Ababa and the rural district of Kersa
}

\author{
Lilia Bliznashka ,* $\odot$, Mia M Blakstad ${ }^{1} \odot$, Yemane Berhane ${ }^{2}$, Amare W Tadesse ${ }^{2,3}$, \\ Nega Assefa ${ }^{4} \odot$, Goodarz Danaei ${ }^{1,5}$, Chelsey R Canavan ${ }^{1}$, Elena C Hemler $^{1}$ and \\ Wafaie W Fawzi ${ }^{1,5,6}$
}

'Department of Global Health and Population, Harvard T.H. Chan School of Public Health, 665 Huntington Avenue, Building 1, 11 th Floor, Boston, MA 02115 , USA: ${ }^{2}$ Addis Continental Institute of Public Health, Yeka Sub-City, Addis Ababa, Ethiopia: ${ }^{3}$ Department of Infectious Disease Epidemiology, London School of Hygiene \& Tropical Medicine, London, UK: ${ }^{4}$ College of Health and Medical Sciences, Haramaya University, Haramaya, Ethiopia: ${ }^{5}$ Department of Epidemiology, Harvard T.H. Chan School of Public Health, Boston, MA, USA: ${ }^{6}$ Department of Nutrition, Harvard T.H. Chan School of Public Health, Boston, MA, USA

Submitted 4 November 2020: Final revision received 30 July 2021: Accepted 24 August 2021: First published online 27 August 2021

\begin{abstract}
Objective: To examine the prevalence of and factors associated with different forms of household-level double burden of malnutrition (DBM) in Ethiopia.

Design: We defined DBM using anthropometric measures for adult overweight $\left(\mathrm{BMI} \geq 25 \mathrm{~kg} / \mathrm{m}^{2}\right.$ ), child stunting (height-for-age $Z$-score $<-2 \mathrm{sD}$ ) and overweight (weight-for-height $Z$-score $\geq 2 \mathrm{SD}$ ). We considered sixteen biological, environmental, behavioural and socio-demographic factors. Their association with DBM forms was assessed using generalised linear models.

Setting: We used data from two cross-sectional studies in an urban (Addis Ababa, January-February 2018), and rural setting (Kersa District, June-September 2019). Participants: Five hundred ninety-two urban and 862 rural households with an adult man, adult woman and child $<5$ years.

Results: In Addis Ababa, overweight adult and stunted child was the most prevalent DBM form $(9 \%(95 \%$ CI 7, 12)). Duration of residence in Addis Ababa (adjusted OR (aOR) 1.03 (95\% CI 1.00, 1.06)), Orthodox Christianity (aOR 1.97 (95\% CI 1.01, 3.85)) and household size (aOR 1.24 (95\% CI 1.01, 1.54)) were associated factors. In Kersa, concurrent child overweight and stunting was the most prevalent DBM form (11\% (95\% CI 9, 14)). Housing quality (aOR 0.33 (95\% CI 0.20, 0.53)), household wealth (aOR 1.92 (95\% CI 1.18, 3.11) and sanitation (aOR 2.08 (95\% CI 1.07, 4.04)) were associated factors. After adjusting for multiple comparisons, only housing quality remained a significant factor.

Conclusions: DBM prevalence was low among urban and rural Ethiopian households. Environmental, socio-economic and demographic factors emerged as potential associated factors. However, we observed no common associated factors among urban and rural households.
\end{abstract}

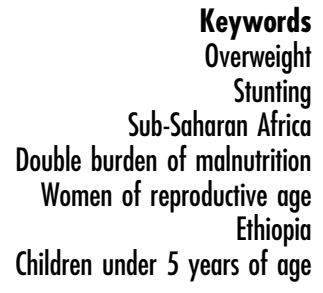

Malnutrition is a major public health concern in low- and middle-income countries (LMIC). It has remained the highest-ranking risk factor for disability since 1990, accounting for $20 \%$ of disability-adjusted life years in $2017^{(1)}$. In Ethiopia, undernutrition is prevalent: $22 \%$ of women and $33 \%$ of men are underweight, $38 \%$ of children $<5$ years of age are stunted, and $10 \%$ are wasted ${ }^{(2)}$. Although nationally only $8 \%$ of women and $3 \%$ of men are overweight, larger urban-rural disparities exist. In 2016, women's overweight prevalence was $21 \%$ in urban areas and $4 \%$ in rural areas, whereas men's overweight was $12 \%$ and $1 \%$, respectively. The Addis Ababa region had the highest overweight prevalence: $29 \%$ among women and $21 \%$ among men ${ }^{(2)}$. Despite progress over the past three decades, undernutrition remains the primary risk factor for $24 \%$ of all deaths in Ethiopia and $63 \%$ of deaths among children $<5$ years of age ${ }^{(1)}$.

At the household level, the most common double burden of malnutrition (DBM) definitions encompass 
women of reproductive age and children $<5$ years of age ${ }^{(3)}$. A 2019 Lancet DBM Series defined four types of householdlevel DBM covering these populations: (1) concurrent child overweight and stunting; (2) overweight woman and at least one wasted child; (3) overweight woman and at least one stunted child; and (4) underweight woman and at least one overweight child ${ }^{(4)}$. In sub-Saharan Africa (SSA), total household-level DBM (i.e. presence of any of these four forms) prevalence ranges from a low of $6.02 \%$ in Ethiopia to a high of $26.96 \%$ in Sao Tome and Principe $^{(4)}$. However, national household-level DBM estimates may mask within-country disparities. In SSA, women's overweight and obesity are growing faster in urban than in rural settings ${ }^{(5)}$, suggesting household-level DBM may differ across geographical settings. In fact, the odds of an overweight woman and a stunted child in the same household are 1.24 higher in urban and peri-urban areas than in rural areas across thirty SSA countries ${ }^{(6)}$.

In Ethiopia, no studies to date have comprehensively examined household-level DBM and its correlates, apart from the 2019 Lancet DBM Series. This Series supplied nationally representative estimates of the prevalence of four forms of household-level DBM but did not provide urban and rural estimates separately ${ }^{(4)}$. No other national or sub-national estimates of other forms of household-level DBM exist. Prior studies have focused on describing the population-level burden of malnutrition and its associated factors. Using nationally representative Demographic and Health Survey (DHS) data, most prior studies aimed to identify the prevalence and factors associated with women's or children's underweight, overweight and obesity $^{(7-11)}$. Only one of these studies included adult men and examined the population-level prevalence and correlates of adult underweight and overweight ${ }^{(11)}$.

According to the WHO framework on the drivers of DBM, DBM is attributable to a diverse set of biological, environmental, behavioural, and social and demographic determinants $^{(12)}$. More recently, the biological determinants, such as epigenetics and early-life nutrition, have been highlighted ${ }^{(13)}$. Given the lack of empirical studies of household-level DBM, its correlates in Ethiopia remain largely unknown. Farah $e t$ al. showed that socio-economic (i.e. low household wealth) and biological (i.e. male gender, older age, small birth size and no vitamin A supplementation in the past 6 months) factors are associated with concurrent overweight and stunting in children 6-24 months of age ${ }^{(14)}$. Studies from other SSA countries have also found women's short stature, age, and education, and household size as socio-economic and demographic factors associated with concurrent child overweight and stunting ${ }^{(15)}$. With respect to other forms of household-level DBM, evidence is lacking. Only two studies from West Africa have identified socio-economic and demographic factors associated with overweight woman and stunted child $^{(16,17)}$, and one study from Benin showed that socioeconomic status and dietary diversity were the primary associated factors of overweight woman and wasted or stunted child ${ }^{(18)}$. To our knowledge, no studies have examined the correlates of overweight woman and wasted child, and underweight woman and overweight child in SSA. Likewise, no studies on household-level DBM in SSA have included adult men. Further, behavioural (e.g. diet) and environmental (e.g. food supply and cost, or cultural and social aspects) factors associated with DBM are also understudied.

Therefore, we sought to describe household-level DBM and its associated factors among urban and rural Ethiopian households with men and women of reproductive age, and children $<5$ years of age. To our knowledge, this is the first study to provide estimates of household-level DBM including men and to identify the associated factors of multiple forms of household-level DBM across urban and rural settings in Ethiopia. In addition, based on the associated factors we identified, we suggest some potential doubleduty actions to address DBM in the country.

\section{Methods}

\section{Data and participants}

We used data from two cross-sectional studies conducted in an urban setting - the capital Addis Ababa (JanuaryFebruary 2018), and a rural setting - Kersa district (June-September 2019). The primary objectives of the two studies were to characterise protein source food production, access, and consumption and to quantify the health and environmental impacts of optimising Ethiopian diets. The two studies employed similar multistage sampling strategies, inclusion and exclusion criteria, and quantitative questionnaires. In Addis Ababa, five out of the ten sub-cities into which Addis Ababa is subdivided were randomly selected at the first stage. Within each of the five randomly selected sub-cities, two districts were chosen at random at the second stage. Within each district, approximately 240 households were screened. Households with at least one woman of reproductive age (18-49 years) and a child aged 6-59 months were invited to participate in the study. If more than one woman of reproductive age lived in the household and was present at the time of the interview, one was randomly selected for the interview using a random number generator. If a selected woman had more than one child aged 6-59 months, one child was selected for the interview using a random number generator. The women we interviewed were the biological mother of the child (96\%), grandmothers (1.9\%), aunts (1.43\%) or another female household member (0.58\%). When present, the woman's adult male partner ( $\geq 18$ years) was also interviewed. If he was not present, another adult man was interviewed, and if more than one man was present, one was randomly selected. Thus, the women and men we interviewed were not always the biological parents of the child, and the men 
were not always the partners/husbands of the interviewed women. A total of 1050 households participated in the Addis Ababa study.

Kersa is a predominantly rural agricultural district is Eastern Ethiopia. At the first stage, the twenty-four kebeles (lowest administrative unit) from the Kersa Demographic Surveillance and Health Research Centre (KDS-HRC) of Haramaya University ${ }^{(19)}$ were stratified into rural ( $n$ 21) and urban $(n 3)$ kebeles. The three urban kebeles represent small towns, which have 24-h electricity supply ${ }^{(19)}$. Electricity supply was the only criterion used to classify Kersa kebeles into urban and rural. As compared to Addis Ababa, Kersa district is still considered rural given the limited availability of electricity and that most inhabitants are farmers ${ }^{(19)}$. At the second stage, ten out of the twenty-one rural kebeles and two out of the three urban kebeles were randomly selected. Households with at least one woman of reproductive age (18-49 years old), a child 659 months of age and an adult man ( $\geq 18$ years) were randomly selected from the KDS-HRC database. Pregnant women were excluded from the study. If more than one target individual was present at the time of the interview, one was randomly selected using the same procedures as in the Addis Ababa sample. Most women (99.4\%) we interviewed were the biological mothers of the child. However, since adult men could be randomly selected, they were not always the biological fathers of the interviewed children or the partner/husband of the interviewed woman. A total of 1197 households participated in the Kersa study. In both Addis Ababa and Kersa, the overall number of clusters at the first stage and the number of households at the second stage were based on logistical and financial constraints.

Identical quantitative household questionnaires were used in both studies to collect information on socioeconomic and demographic characteristics, household food security, food supply shortages, food expenditures, and participants' diets. Trained fieldworkers directly assessed participants' height and weight. Both adults and children were barefoot and wore light clothing for the assessment. Height was measured to the nearest $0.1 \mathrm{~cm}$ and weight to the nearest $0 \cdot 1 \mathrm{~kg}$. Adult height and height for children 24-59 months of age was measured using a Seca stadiometer. Length of children $<24$ months of age was measured using a length board. Weight was measured using a Seca digital scale.

Participants' diet was assessed using a non-quantitative food frequency questionnaire (FFQ), locally adapted from a semi-quantitative FFQ version validated for use among urban Tanzanian adults ${ }^{(20)}$. Adult men and women were asked if they consumed each of seventy-three individual foods in the past $7 \mathrm{~d}$, and if they had, they were then asked if they consumed the food in the past $24 \mathrm{~h}$. The FFQ included locally available foods and varieties, and an option to specify other foods. Portion sizes and frequencies of intake were not collected. Women reported on children's dietary intake.

\section{Outcome measures}

Adult body mass index (BMI) was calculated as weight (kg) divided by height $(\mathrm{m})$ squared. We categorised adults as underweight $\left(\mathrm{BMI}<18 \mathrm{~kg} / \mathrm{m}^{2}\right)$, normal weight $\left(\mathrm{BMI} \geq 18.5 \mathrm{~kg} / \mathrm{m}^{2}\right.$ and $\mathrm{BMI}<25 \mathrm{~kg} / \mathrm{m}^{2}$ ), or overweight $\left(\mathrm{BMI} \geq 25 \mathrm{~kg} / \mathrm{m}^{2}\right)^{(21)}$. We calculated child length/heightfor-age $Z$-score (HAZ) and weight-for-length/height $Z$ score (WHZ) using the 2006 WHO Child Growth Standards ${ }^{(22)}$. Stunting was defined as $\mathrm{HAZ}<-2 \mathrm{SD}$, wasting as $\mathrm{WHZ}<-2 \mathrm{SD}$ and overweight as $\mathrm{WHZ} \geq 2 \mathrm{SD}$.

Using these anthropometric indicators, we calculated fifteen forms of household-level DBM encompassing most forms of malnutrition within the same individual, pairs of individuals or multiple individuals that can be defined based on anthropometry. Within the same individual, we defined DBM as concurrent child overweight and stunting. Within pairs of individuals, we defined DBM as overweight woman or man and stunted or wasted child, underweight woman or man and overweight child, and overweight woman or man and underweight man or woman. Within households, we defined DBM as at least one overweight adult and wasted or stunted child, at least one underweight adult and overweight child, two overweight adults and wasted or stunted child, and two underweight adults and overweight child. For each DBM form, we created binary indicators where $1=\mathrm{DBM}$ form was present and $0=$ otherwise.

\section{Double burden of malnutrition associated factors}

We considered sixteen DBM factors grouped along the WHO drivers of DBM framework. This framework outlines the biological (e.g. epigenetics and early-life experiences), environmental (e.g. food supply and systems, food portion size and cost, urban and built environment), behavioural (e.g. lifestyle and psychological factors), and socio-economic and demographic factors of DBM (e.g. poverty and food insecurity $)^{(12)}$. The biological factors we included were child age and sex, and women's age. The environmental factors were the number of food supply shortages in the past year (range 0-13), distance to market (in km), monthly food expenditures as a proxy of food cost (total household expenditures on meat, fish, poultry, pulses, nuts and seeds, and fats and oils in the past month), religion (Christian Orthodox $v$. non-Christian Orthodox) and duration of residence (number of years living in Addis Ababa or Kersa). In Kersa, distance to market and food expenditures were only available for a subset of households and were therefore not considered as associated factors in this sample since doing so may introduce bias if the households with data on distance to market and food expenditures are systematically different from households without this data. Religion and duration of residence served as proxies for cultural and social practices. In Ethiopia, Orthodox Christians abstain from animal source foods and fats for $180 \mathrm{~d}$ throughout the year ${ }^{(23)}$. Given the differential 
association between animal source foods consumption and overweight risk, e.g. higher egg, dairy or fish consumption does not increase overweight risk in adults, whereas higher red meat and processed meat consumption does ${ }^{(24)}$, we had no a priori hypotheses about the association between religion and household-level DBM.

Diet was the only behavioural factor we considered. We assessed women's dietary diversity using the minimum dietary diversity for women (MDD-W) indicator ${ }^{(25)}$. We grouped foods into ten non-overlapping food groups and summed them into a dietary diversity score (DDS-W, range 0-10). We categorised women as meeting MDD if they consumed at least five food groups (DDS $\geq 5$ ). MDD-W serves as a proxy for micronutrient adequacy ${ }^{(26)}$. In the absence of similar indicators validated for use among adult men $\geq 18$ years of age, we created the same indicators for dietary diversity and minimum dietary diversity. Children's dietary diversity was assessed using the WHO indicators for dietary diversity score (DDS, range 0-7) and minimum dietary diversity (MDD, defined as DDS $\geq 4)^{(27)}$. Although not originally designed to assess diet in children older than 24 months of age, a recent study showed that both DDS and MDD can serve as adequate proxies for micronutrient intake in children of 24-59 months of age ${ }^{(28)}$. MDD showed $79 \%$ specificity and $56 \%$ sensitivity in correctly classifying children with probability of adequacy $>80 \%$ for eleven micronutrients ${ }^{(28)}$. Given this evidence and the absence of other diet indicators validated for use among children of 24-59 months of age, we used the same indicators for all children of 6-59 months of age. All diet indicators were based on a $24-\mathrm{h}$ recall. In secondary analyses, we recalculated all diet indicators based on a 7-d recall since onequarter of Addis Ababa households reported that the day prior to the FFQ administration was a fasting day and thus the 24-h recall may potentially underestimate dietary diversity in these households.

Finally, the socio-economic and demographic factors we included were household wealth, housing floor quality (parquet or polished floor $v$. natural floor), sanitation, food security, household size, women's and men's education (primary or higher $v$. no or incomplete primary), and women's employment (engaged $v$. not engaged in an income generating activity). To assess household wealth, we derived wealth indices separately for the full Addis Ababa sample and the full Kersa sample using principal component analysis based on items representing housing quality and asset ownership (twelve items in Addis Ababa and ten items in Kersa). The wealth quartiles were defined separately for the full Addis Ababa sample and the full Kersa sample. We then created a binary indicator for whether a household belonged to the lowest wealth quartile or to a higher wealth quintile. Household sanitation was assessed using an indicator for whether the household had access to an improved latrine. Although housing floor quality and sanitation were included in the wealth indices, we also considered them separately, since unimproved sanitation is the second most important risk factor for child stunting in Ethiopia ${ }^{(29)}$. Household food security was assessed using the Household Food Insecurity Access Scale ${ }^{(30)}$.

\section{Analytic samples}

In both Addis Ababa and Kersa, we restricted the samples to households with available anthropometric measurements for all three individuals: woman of reproductive age (18-49 years), adult man ( $\geq 18$ years) and child (6-59 months). In Addis Ababa, we excluded 392 households in which an adult man was not interviewed. We further excluded pregnant women ( $n$ 56) to harmonise the urban sample with the rural sample, which did not recruit pregnant women. Finally, ten children with abnormal HAZ or WHZ scores (above or below $6 \mathrm{SD}$ ) were also excluded. The final analytic sample in Addis Ababa consisted of 592 households. In Kersa, 335 households where at least one household member was missing anthropometric data were excluded. The final analytic sample in Kersa was 862 households. Supplemental Figures 1 and 2 provide flow charts of how the analytic samples were derived.

In each sample, we compared household and women's demographic characteristics among households included in the analytic sample and those excluded using Wald tests. Differences were considered statistically significant at $P<0 \cdot 05$. Overall, there were few differences between included and excluded households in either sample. Only one statistically significant difference was observed in Addis Ababa, where excluded households were significantly smaller than included households (data not shown). As a result, we did not expect the exclusion of households from either sample to bias our results.

\section{Statistical analysis}

We used generalised linear models to assess the univariate and multivariate relationships between household-level DBM forms and the biological, environmental, behavioural, and socio-economic and demographic factors. DBM factors were investigated only for DBM forms prevalent in $\geq 5 \%$ of households in either the Addis Ababa or Kersa sample. We estimated unadjusted OR (uOR) and $95 \%$ CI from univariate models and adjusted OR (aOR) and $95 \% \mathrm{CI}$ from multivariate models. Since factors were selected $a$ priori based on the WHO drivers of DBM framework, multivariate models included all factors regardless of whether they were statistically significant in univariate models. Where both a continuous and binary indicator were considered in univariate models (e.g. DDS and MDD), we entered only the continuous indicator in the multivariate model to increase power. Our assessment of the biserial correlations between all the factors included in the multivariate model indicated no presence of multicollinearity, that is, all correlations were between -0.44 and 0.52 in Addis Ababa and -0.35 and 0.43 in 
Table 1 Characteristics of the households included in the Addis Ababa and Kersa samples

\begin{tabular}{|c|c|c|c|c|c|c|}
\hline & \multicolumn{3}{|c|}{ Addis Ababa ( $n$ 592) } & \multicolumn{3}{|c|}{ Kersa $(n 862)$} \\
\hline & Mean or $n$ & $\%$ & SD & Mean or $n$ & $\%$ & SD \\
\hline \multicolumn{7}{|l|}{ Household characteristics } \\
\hline Size & 4.6 & & 1.6 & $5 \cdot 9$ & & $3 \cdot 1$ \\
\hline In poorest wealth quartile & 136 & $23 \%$ & & 306 & $35.5 \%$ & \\
\hline Has parquet/polished floor & 370 & $62.5 \%$ & & 49 & $5.7 \%$ & \\
\hline Has access to an improved latrine & 484 & $81.8 \%$ & & 61 & $7.1 \%$ & \\
\hline Is food-secure & 369 & $62.3 \%$ & & 742 & $86.1 \%$ & \\
\hline Number of food supply shortages experienced & $1 \cdot 0$ & & $2 \cdot 8$ & $11 \cdot 7$ & & $2 \cdot 7$ \\
\hline Food expenditures (Ethiopian Birr) & 1230 & & 1096 & - & & \\
\hline Distance to market $(\mathrm{km})$ & $2 \cdot 2$ & & $6 \cdot 2$ & - & & \\
\hline \multicolumn{7}{|l|}{ Woman's characteristics' } \\
\hline Age (in years) & $30 \cdot 1$ & & $5 \cdot 7$ & $31 \cdot 0$ & & $6 \cdot 2$ \\
\hline Has primary education or higher & 372 & $62 \cdot 8 \%$ & & 333 & $38.6 \%$ & \\
\hline Is an Orthodox Christian & 441 & $74.5 \%$ & & 29 & $3.4 \%$ & \\
\hline Woman is engaged in an income generating activity & 200 & $33.8 \%$ & & 856 & $99.3 \%$ & \\
\hline Duration of residence (in years) & $19 \cdot 3$ & & $10 \cdot 9$ & 31.7 & & $7 \cdot 8$ \\
\hline $\mathrm{BMl} \mathrm{kg} / \mathrm{m}^{2}$ & $24 \cdot 0$ & & 4.6 & $21 \cdot 0$ & & $2 \cdot 8$ \\
\hline \multicolumn{7}{|l|}{ BMI category } \\
\hline Underweight $\left(<18 \mathrm{~kg} / \mathrm{m}^{2}\right)$ & 57 & $9.6 \%$ & & 143 & $16 \cdot 6 \%$ & \\
\hline Normal weight $\left(\geq 18 \mathrm{~kg} / \mathrm{m}^{2}\right.$ and $\left.<25 \mathrm{~kg} / \mathrm{m}^{2}\right)$ & 315 & $53 \cdot 2 \%$ & & 653 & $75.8 \%$ & \\
\hline Overweight $\left(\geq 25 \mathrm{~kg} / \mathrm{m}^{2}\right)$ & 220 & $37 \cdot 2 \%$ & & 66 & $7.7 \%$ & \\
\hline Dietary diversity score (DDS, range $0-10$ ) in the past $24 \mathrm{~h}$ & 3.7 & & 1.5 & 3.7 & & 1.4 \\
\hline Minimum dietary diversity (DDS $\geq 5$ ) in the past $24 \mathrm{~h}$ & 157 & $26.5 \%$ & & 222 & $25.8 \%$ & \\
\hline \multicolumn{7}{|l|}{ Man's characteristics } \\
\hline Has primary education or higher & 423 & $71.5 \%$ & & 376 & $43.6 \%$ & \\
\hline BMI $\mathrm{kg} / \mathrm{m}^{2}$ & 23.0 & & $3 \cdot 3$ & $21 \cdot 1$ & & $3 \cdot 0$ \\
\hline BMI category & & & & & & \\
\hline Underweight $\left(<18 \mathrm{~kg} / \mathrm{m}^{2}\right)$ & 49 & $8.3 \%$ & & 124 & $14.4 \%$ & \\
\hline Normal weight $\left(\geq 18 \mathrm{~kg} / \mathrm{m}^{2}\right.$ and $\left.<25 \mathrm{~kg} / \mathrm{m}^{2}\right)$ & 395 & $66.7 \%$ & & 687 & $79 \cdot 7 \%$ & \\
\hline Overweight $\left(\geq 25 \mathrm{~kg} / \mathrm{m}^{2}\right)$ & 148 & $25 \%$ & & 51 & $5.9 \%$ & \\
\hline DDS (range $0-10$ ) in the past $24 \mathrm{~h}$ & 3.7 & & 1.5 & $3 \cdot 2$ & & $1 \cdot 7$ \\
\hline Minimum dietary diversity (DDS $\geq 5$ ) in the past $24 \mathrm{~h}$ & 143 & $24.2 \%$ & & 170 & $19.9 \%$ & \\
\hline \multicolumn{7}{|l|}{ Child's characteristics } \\
\hline Age (in months) & $29 \cdot 0$ & & 14.9 & $30 \cdot 2$ & & $16 \cdot 1$ \\
\hline Female & 276 & $46.6 \%$ & & 399 & $46 \cdot 3 \%$ & \\
\hline Length/height-for-age Z-score (HAZ) & -0.7 & & 1.6 & $-2 \cdot 1$ & & $2 \cdot 5$ \\
\hline Stunted (HAZ <-2 SD) & 110 & $18.6 \%$ & & 488 & $56.6 \%$ & \\
\hline Weight-for-age Z-score (WAZ) & -0.1 & & $1 \cdot 3$ & $-1 \cdot 4$ & & $1 \cdot 7$ \\
\hline Underweight (WAZ <-2 SD) & 29 & $4.9 \%$ & & 289 & $33.5 \%$ & \\
\hline Weight-for-length/height Z-score (WHZ) & 0.3 & & 1.5 & -0.2 & & $2 \cdot 2$ \\
\hline Wasted $(\mathrm{WHZ}<-2 \mathrm{SD})$ & 25 & $4.2 \%$ & & 164 & $19 \%$ & \\
\hline Overweight (WHZ $\geq 2 \mathrm{SD})$ & 69 & $11.7 \%$ & & 121 & $14 \%$ & \\
\hline DDS (range $0-7$ ) in the past $24 \mathrm{~h}$ & $2 \cdot 8$ & & 1.3 & $3 \cdot 1$ & & 1.4 \\
\hline Minimum dietary diversity (DDS $\geq 4$ ) in the past $24 \mathrm{~h}$ & 165 & $27.9 \%$ & & 314 & $36.5 \%$ & \\
\hline
\end{tabular}

Kersa (data not shown). Missing values on any of the factors were imputed using mean cluster-level imputation. Standard errors were clustered at the lowest administrative level in each sample: woreda in Addis Ababa and kebele in Kersa. Associations were considered statistically significant at $P<0.05$. Given the exploratory nature of the analyses, we also present $\mathrm{p}$-values corrected for multiple comparisons using the Benjamini and Yekutieli method, which controls the false discovery rate under dependency ${ }^{(31)}$. All analyses were performed using Stata 16(32).

\section{Results}

Characteristics of the two analytic samples are shown in Table 1. Overall, Addis Ababa households had better living conditions than Kersa households. Although most households in both samples were food-secure, rural households experienced more food supply shortages in the past year than urban households. Generally, overnutrition was more prevalent in Addis Ababa, whereas undernutrition was more prevalent in Kersa. In Kersa, women's employment and religion were not considered as associated factors due to lack of variability in the sample: $99.3 \%$ of women were employed and only $3.4 \%$ were Orthodox Christians. The higher frequency of women's employment in Kersa relative to Addis Ababa was likely due to women being engaged in agricultural activities (given that Kersa is predominantly an agricultural district).

The combination of overweight adult and stunted child was the most prevalent form of household-level DBM in Addis Ababa (Table 2). Overweight woman and stunted child, and concurrent child overweight and stunting were also prevalent. The remaining forms of household-level 
Table 2 Household-Level forms of malnutrition in Addis Ababa and Kersa

\begin{tabular}{|c|c|c|c|c|c|c|c|}
\hline & \multirow[b]{2}{*}{ National estimates* } & \multicolumn{3}{|c|}{ Addis Ababa $(n 592)$} & \multicolumn{3}{|c|}{ Kersa $(n 862)$} \\
\hline & & $n$ & $\%$ & $95 \% \mathrm{Cl}$ & $n$ & $\%$ & $95 \% \mathrm{Cl}$ \\
\hline Concurrent child overweight and stunting & $2.93 \%$ & 22 & 3.72 & $2 \cdot 19,5 \cdot 24$ & 99 & 11.48 & $9 \cdot 35,13.62$ \\
\hline Overweight woman and wasted child & $0.47 \%$ & 10 & 1.69 & $0.65,2.73$ & 13 & 1.51 & $0 \cdot 69,2 \cdot 32$ \\
\hline Overweight woman and stunted child & $1.59 \%$ & 42 & 7.09 & $5 \cdot 02,9 \cdot 17$ & 24 & $2 \cdot 78$ & $1.68,3.88$ \\
\hline Underweight woman and overweight child & $0.74 \%$ & 4 & 0.68 & $0.01,1.33$ & 18 & 2.09 & $1.13,3.04$ \\
\hline Overweight man and wasted child & & 10 & 1.69 & $0.65,2.73$ & 7 & 0.81 & $0 \cdot 21,1 \cdot 41$ \\
\hline Overweight man and stunted child & & 24 & 4.05 & $2.46,5.65$ & 25 & 2.90 & $1.78,4.02$ \\
\hline Underweight man and overweight child & & 4 & 0.68 & $0.01,1.33$ & 14 & 1.62 & $0.78,2.47$ \\
\hline At least one overweight adult and wasted child & & 15 & 2.53 & $1 \cdot 26,3 \cdot 80$ & 19 & $2 \cdot 20$ & $1 \cdot 22,3 \cdot 19$ \\
\hline At least one overweight adult and stunted child & & 55 & $9 \cdot 29$ & $6.95,11.63$ & 44 & $5 \cdot 10$ & $3.63,6.58$ \\
\hline At least one underweight adult and overweight child & & 7 & $1 \cdot 18$ & $0.31,2.05$ & 25 & 2.90 & $1.78,4.02$ \\
\hline $\begin{array}{l}\text { Overweight woman, underweight man, and no child stunting } \\
\text { or wasting }\end{array}$ & & 5 & 0.84 & $0.11,1.58$ & 1 & $0 \cdot 12$ & $-0.11,0.34$ \\
\hline $\begin{array}{l}\text { Underweight woman, overweight man, and no child stunting } \\
\text { or wasting }\end{array}$ & & 7 & $1 \cdot 18$ & $0.31,2.06$ & 1 & $0 \cdot 12$ & $-0.11,0.34$ \\
\hline Two overweight adults and wasted child & & 5 & 0.84 & $0.11,1.58$ & 1 & 0.12 & $-0.11,0.34$ \\
\hline Two overweight adults and stunted child & & 11 & $1 \cdot 86$ & $0.77,2.95$ & 5 & 0.58 & $0.07,1.09$ \\
\hline Two underweight adults and overweight child & & 1 & 0.17 & $-0.16,0.50$ & 7 & 0.81 & $0.21,1.41$ \\
\hline
\end{tabular}

*Nationally representative estimates based on the 2016 Ethiopian Demographic and Health Survey.

Only estimates for the first four forms of household-level malnutrition available ${ }^{(4)}$.

DBM occurred in $<5 \%$ of the sample, with many occurring in $<10$ households. In contrast, concurrent child overweight and stunting was the most prevalent form of household-level DBM in Kersa, affecting $11 \%$ of children. Overweight adult and stunted child was the only other form of DBM affecting $\geq 5 \%$ of households.

In Addis Ababa, older children were less likely to be concurrently overweight and stunted (uOR 0.96 (95\% CI 0.94, 0.98)), whereas children of employed women, relative to unemployed, were more likely to be concurrently overweight and stunted 2.02 (95\% CI 1.14, 3.56) (Table 3). After correcting for multiple comparisons, only child age remained a significant factor. In the multivariate model, child age and women's employment were similarly associated with concurrent child overweight and stunting (Table 4). However, only women's employment was significant after correcting for multiple comparisons. In Kersa, more food supply shortages, women and men meeting MDD in the past $24 \mathrm{~h}$, and improved housing floor quality were associated with lower odds of concurrent child overweight and stunting in univariate models (Table 5). In contrast, lower household wealth was associated with increased odds of this form of DBM (uOR 2.21 (95\% CI $1.58,3.09)$ ). After correcting for multiple comparisons, men's MDD in the past $24 \mathrm{~h}$, household wealth and housing floor quality remained significant associated factors. In the multivariate model, improved housing floor quality was associated with lower odds of concurrent child overweight and stunting, whereas low household wealth and access to an improved latrine were associated with higher odds (Table 6). However, only housing floor quality was significant after the p-value correction for multiple hypotheses testing. In the secondary analyses using a 7-d recall period for all diet indicators, diet did not predict concurrent child overweight and stunting in Addis Ababa in neither the univariate nor the multivariate analyses (see online Supplemental Tables 1 and 2). Women and men's DDS and MDD in the past $7 \mathrm{~d}$ were significant associated factors of concurrent overweight and stunting in Kersa in univariate analyses (though only women's DDS and MDD in the past $7 \mathrm{~d}$ remained significant after the multiple comparisons correction), but not in multivariate analyses (see online Supplemental Tables 3 and 4).

Older women's age, longer duration of residence in Addis Ababa and larger household size were associated with higher odds of overweight woman and stunted child in Addis Ababa, though only the first two remained statistically significant after the multiple hypothesis correction (Table 3). In the multivariate model, duration of residence remained a significant factor (Table 4), though it was no longer significant after correcting for multiple comparisons. In contrast, in Kersa, we found no significant factors associated with overweight woman and stunted child in univariate models (Table 5). In the multivariate model, older child's age was associated with higher odds of overweight woman and stunted child but did not remain significant after correcting for multiple hypothesis testing (Table 6). In the secondary analyses using the 7 -d recall diet indicators, higher men's dietary diversity was associated with higher odds of overweight woman and stunted child in the multivariate model for Addis Ababa (see online Supplemental Table 2), but in the univariate model or in Kersa.

Lastly, the univariate factors associated with overweight adult and stunted child in Addis Ababa were the same as those of overweight woman and stunted child: older women's age, longer duration of residence in the city and larger household size (Table 3). Only women's age and duration of residence remained significant after adjustment for multiple comparisons. In the multivariate model, 
Table 3 Univariate factors associated with household-level forms of double burden of malnutrition in Addis Ababa

\begin{tabular}{|c|c|c|c|c|c|c|c|c|c|c|c|c|}
\hline & \multicolumn{4}{|c|}{ Concurrent child overweight and stunting } & \multicolumn{4}{|c|}{ Overweight woman and stunted child } & \multicolumn{4}{|c|}{$\begin{array}{l}\text { At least one overweight adult and } \\
\text { stunted child }\end{array}$} \\
\hline & $\begin{array}{l}\beta \text { or } \\
\text { OR }\end{array}$ & $95 \% \mathrm{Cl}$ & $P$-value & $\begin{array}{l}\text { Corrected } \\
P \text {-value }\end{array}$ & $\begin{array}{l}\beta \text { or } \\
\text { OR }\end{array}$ & $95 \% \mathrm{Cl}$ & $P$-value & $\begin{array}{c}\text { Corrected } \\
P \text {-value }\end{array}$ & $\begin{array}{l}\beta \text { or } \\
\text { OR }\end{array}$ & $95 \% \mathrm{Cl}$ & $P$-value & $\begin{array}{c}\text { Corrected } \\
P \text {-value }\end{array}$ \\
\hline \multicolumn{13}{|l|}{ Biological } \\
\hline Child age (in months) & 0.96 & $0.94,0.98$ & $<0.001$ & $<0.001$ & 1.01 & $0.99,1.03$ & $0 \cdot 164$ & 0.672 & 1.01 & $0.99,1.02$ & 0.331 & 0.826 \\
\hline Child is female & 1.39 & $0.56,3.45$ & 0.476 & 0.924 & 0.94 & $0.37,2.37$ & 0.899 & 0.950 & $1 \cdot 12$ & $0.51,2.46$ & 0.787 & 0.950 \\
\hline Woman's age (in years) & 0.95 & $0.90,1.01$ & 0.087 & 0.479 & 1.09 & $1.03,1.14$ & 0.001 & 0.017 & 1.07 & $1.03,1.11$ & 0.001 & 0.017 \\
\hline \multicolumn{13}{|l|}{ Environmental } \\
\hline Food supply shortage & 1.02 & $0.92,1.13$ & 0.713 & 0.950 & 1.03 & $0.97,1.10$ & 0.261 & 0.826 & 1.02 & $0.97,1.08$ & 0.384 & 0.826 \\
\hline Distance to market (in km) & 0.80 & $0.58,1.09$ & $0 \cdot 161$ & 0.671 & 0.93 & $0.84,1.03$ & 0.157 & 0.672 & 0.99 & $0.94,1.04$ & 0.601 & 0.950 \\
\hline Food expenditures (in Ethiopian birr) & 1.00 & $1.00,1.00$ & 0.671 & 0.950 & 1.00 & $1.00,1.00$ & 0.939 & 0.950 & 1.00 & $1.00,1.00$ & 0.690 & 0.950 \\
\hline Woman is an Orthodox Christian & 0.72 & $0.17,3.04$ & 0.659 & 0.950 & 1.49 & $0.69,3.24$ & 0.310 & 0.826 & 1.60 & $0.72,3.55$ & 0.246 & 0.826 \\
\hline Duration of residence (in years) & 1.00 & $0.96,1.03$ & 0.856 & 0.950 & 1.06 & $1.02,1.10$ & 0.001 & 0.017 & 1.04 & $1.01,1.07$ & 0.003 & 0.040 \\
\hline \multicolumn{13}{|l|}{ Behavioural } \\
\hline Woman's dietary diversity score in the past $24 \mathrm{~h}$ & 0.91 & $0.71,1.17$ & 0.449 & 0.898 & 0.99 & $0.81,1.21$ & 0.928 & 0.950 & 1.05 & $0.90,1.22$ & 0.543 & 0.950 \\
\hline Woman's minimum dietary diversity in the past $24 \mathrm{~h}$ & 1.04 & $0.42,2.59$ & 0.932 & 0.950 & 0.74 & $0.39,1.40$ & 0.355 & 0.826 & 1.04 & $0.62,1.75$ & 0.872 & 0.950 \\
\hline Man's dietary diversity score in the past $24 \mathrm{~h}$ & 0.86 & $0.69,1.06$ & 0.162 & 0.672 & 0.88 & $0.77,1.01$ & 0.071 & 0.469 & 0.92 & $0.82,1.05$ & 0.210 & 0.770 \\
\hline Man's minimum dietary diversity in the past $24 \mathrm{~h}$ & 0.48 & $0.22,1.09$ & 0.079 & 0.474 & 0.85 & $0.38,1.90$ & 0.686 & 0.950 & 0.86 & $0.51,1.46$ & 0.588 & 0.950 \\
\hline Child's dietary diversity score in the past $24 \mathrm{~h}$ & 1.02 & $0.76,1.37$ & 0.888 & 0.950 & 0.96 & $0.79,1.16$ & 0.669 & 0.950 & 1.05 & $0.89,1.23$ & 0.589 & 0.950 \\
\hline Child's minimum dietary diversity in the past $24 \mathrm{~h}$ & 1.50 & $0.64,3.56$ & 0.354 & 0.826 & 0.91 & $0.46,1.82$ & 0.795 & 0.950 & 1.07 & $0.61,1.88$ & 0.819 & 0.950 \\
\hline \multicolumn{13}{|l|}{ Socio-economic and demographic } \\
\hline Low household wealth & 1.27 & $0.36,4.53$ & 0.713 & 0.950 & 0.78 & $0.29,2 \cdot 10$ & $0 \cdot 617$ & 0.950 & 0.93 & $0.44,1.95$ & 0.846 & 0.950 \\
\hline High housing floor quality & 1.30 & $0.45,3.78$ & 0.633 & 0.950 & 1.37 & $0.68,2.76$ & 0.384 & 0.826 & 1.52 & $0.83,2.76$ & 0.173 & 0.672 \\
\hline Household has access to improved latrines & 0.58 & $0.20,1.69$ & 0.320 & 0.826 & 1.12 & $0.44,2.91$ & 0.808 & 0.950 & 1.59 & $0.62,4.07$ & 0.335 & 0.826 \\
\hline Household is food secure & 0.87 & $0.38,1.96$ & 0.734 & 0.950 & 0.98 & $0.53,1.81$ & 0.950 & 0.950 & 0.83 & $0.58,1.17$ & 0.287 & 0.826 \\
\hline Household size & 1.02 & $0.84,1.23$ & 0.852 & 0.950 & 1.26 & $1.07,1.48$ & 0.005 & 0.055 & 1.26 & $1.06,1.49$ & 0.008 & 0.075 \\
\hline Woman has primary education or higher & 1.28 & $0.55,2.97$ & 0.568 & 0.950 & 0.86 & $0.31,2.42$ & 0.776 & 0.950 & 0.95 & $0.42,2 \cdot 18$ & 0.910 & 0.950 \\
\hline Man has primary education or higher & 1.83 & $0.96,3.49$ & 0.065 & 0.469 & 0.70 & $0.29,1.70$ & 0.431 & 0.889 & 0.67 & $0.30,1.49$ & 0.327 & 0.826 \\
\hline Woman is engaged in an income generating activity & 2.02 & $1.14,3.56$ & 0.016 & 0.132 & 1.36 & $0.67,2.76$ & 0.388 & 0.826 & 1.04 & $0.58,1.86$ & 0.900 & 0.950 \\
\hline
\end{tabular}

${ }^{*} P$-value corrected for multiple hypothesis testing using the Benjamini-Yekutieli method to control the false discovery rate. 
Table 4 Multivariate factors associated with household-level forms of double burden of malnutrition in Addis Ababa

\begin{tabular}{|c|c|c|c|c|c|c|c|c|c|c|c|c|}
\hline & \multicolumn{4}{|c|}{ Concurrent child overweight and stunting } & \multicolumn{4}{|c|}{ Overweight woman and stunted child } & \multicolumn{4}{|c|}{ Overweight adult and stunted child } \\
\hline & $\begin{array}{l}\beta \text { or } \\
\text { OR }\end{array}$ & $95 \% \mathrm{Cl}$ & $P$-value & $\begin{array}{c}\text { Corrected } \\
P \text {-value }\end{array}$ & $\begin{array}{l}\beta \text { or } \\
\text { OR }\end{array}$ & $95 \% \mathrm{Cl}$ & $P$-value & $\begin{array}{c}\text { Corrected } \\
P \text {-value }\end{array}$ & $\begin{array}{l}\beta \text { or } \\
\text { OR }\end{array}$ & $95 \% \mathrm{Cl}$ & $P$-value & $\begin{array}{c}\text { Corrected } \\
P \text {-value }\end{array}$ \\
\hline \multicolumn{13}{|l|}{ Biological } \\
\hline Child age (in months) & 0.96 & $0.93,0.99$ & 0.005 & 0.095 & 1.01 & $0.99,1.03$ & 0.253 & 0.753 & 1.00 & $0.98,1.02$ & 0.895 & 0.912 \\
\hline Child is female & 1.42 & $0.52,3.87$ & 0.488 & 0.835 & 1.09 & $0.38,2.94$ & 0.912 & 0.912 & 1.23 & $0.49,3.09$ & 0.661 & 0.874 \\
\hline Woman's age (in years) & 0.95 & $0.89,1.02$ & 0.140 & 0.725 & 1.02 & $0.97,1.07$ & 0.406 & 0.783 & 1.02 & $0.98,1.06$ & 0.320 & 0.760 \\
\hline \multicolumn{13}{|l|}{ Environmental } \\
\hline Food supply shortage & 1.02 & $0.91,1.13$ & 0.766 & 0.881 & 1.04 & $0.97,1.11$ & 0.299 & 0.753 & 1.01 & $0.94,1.07$ & 0.875 & 0.912 \\
\hline Distance to market (in km) & 0.78 & $0.50,1.22$ & 0.272 & 0.753 & 0.94 & $0.86,1.02$ & 0.139 & 0.725 & 1.00 & $0.95,1.04$ & 0.855 & 0.912 \\
\hline Food expenditures (in Ethiopian birr) & 1.00 & $1.00,1.00$ & 0.571 & 0.835 & 1.00 & $1.00,1.00$ & 0.557 & 0.835 & 1.00 & $1.00,1.00$ & 0.211 & 0.753 \\
\hline Woman is an Orthodox Christian & 0.66 & $0.17,2.50$ & 0.539 & 0.835 & 1.47 & $0.76,2.85$ & 0.256 & 0.753 & 1.97 & $1.01,3.85$ & 0.047 & 0.447 \\
\hline Duration of residence (in years) & 1.01 & $0.98,1.04$ & 0.531 & 0.835 & 1.05 & $1.02,1.09$ & 0.004 & 0.095 & 1.03 & $1.00,1.06$ & 0.041 & 0.447 \\
\hline \multicolumn{13}{|l|}{ Behavioural } \\
\hline Woman's dietary diversity score in the past $24 \mathrm{~h}$ & 0.84 & $0.58,1.23$ & 0.372 & 0.783 & $1 \cdot 13$ & $0.83,1.54$ & 0.426 & 0.783 & 1.18 & $0.89,1.56$ & 0.249 & 0.753 \\
\hline Man's dietary diversity score in the past $24 \mathrm{~h}$ & 0.85 & $0.67,1.08$ & 0.182 & 0.753 & 0.83 & $0.69,1.01$ & 0.065 & 0.529 & 0.83 & $0.66,1.05$ & 0.117 & 0.725 \\
\hline Child's dietary diversity score in the past $24 \mathrm{~h}$ & 1.39 & $0.69,2.80$ & 0.362 & 0.783 & 0.96 & $0.74,1.23$ & 0.737 & 0.875 & 1.09 & $0.85,1.40$ & 0.478 & 0.835 \\
\hline \multicolumn{13}{|l|}{ Socio-economic and demographic } \\
\hline Low household wealth & 1.36 & $0.41,4.48$ & 0.618 & 0.859 & $1 \cdot 13$ & $0.48,2.65$ & 0.786 & 0.881 & 1.62 & $0.79,3.33$ & 0.186 & 0.753 \\
\hline High housing floor quality & 1.43 & $0.50,4.10$ & 0.506 & 0.835 & 1.50 & $0.69,3.23$ & 0.304 & 0.753 & 1.81 & $0.89,3.69$ & 0.103 & 0.725 \\
\hline Household has access to improved latrines & 0.61 & $0.19,1.99$ & 0.413 & 0.783 & 1.06 & $0.43,2.60$ & 0.900 & 0.912 & 1.49 & $0.60,3.69$ & 0.394 & 0.783 \\
\hline Household is food secure & 0.78 & $0.33,1.85$ & 0.568 & 0.835 & $1 \cdot 14$ & $0.53,2.47$ & 0.737 & 0.875 & 0.87 & $0.44,1.69$ & 0.675 & 0.874 \\
\hline Household size & 1.04 & $0.84,1.30$ & 0.717 & 0.875 & $1 \cdot 16$ & $0.95,1.41$ & 0.153 & 0.727 & 1.24 & $1.01,1.54$ & 0.041 & 0.447 \\
\hline Woman has primary education or higher & 1.11 & $0.46,2.67$ & 0.814 & 0.892 & 0.74 & $0.24,2.26$ & 0.600 & 0.855 & 0.87 & $0.32,2.39$ & 0.788 & 0.881 \\
\hline Man has primary education or higher & 1.63 & $0.52,4.04$ & 0.399 & 0.783 & 0.65 & $0.29,1.43$ & 0.281 & 0.753 & 0.60 & $0.26,1.40$ & 0.234 & 0.753 \\
\hline Woman is engaged in an income generating activity & $2 \cdot 64$ & $1.54,4.53$ & $<0.001$ & $<0.001$ & $1 \cdot 17$ & $0.61,2 \cdot 24$ & 0.644 & 0.874 & 0.89 & $0.50,1.59$ & 0.698 & 0.874 \\
\hline
\end{tabular}

${ }^{*} P$-value corrected for multiple hypothesis testing using the Benjamini-Yekutieli method to control the false discovery rate. 
Table 5 Univariate factors associated with household-level forms of double burden of malnutrition in Kersa

\begin{tabular}{|c|c|c|c|c|c|c|c|c|c|c|c|c|}
\hline & \multicolumn{4}{|c|}{ Concurrent child overweight and stunting } & \multicolumn{4}{|c|}{ Overweight woman and stunted child } & \multicolumn{4}{|c|}{$\begin{array}{l}\text { At least one overweight adult } \\
\text { and stunted child }\end{array}$} \\
\hline & $\begin{array}{l}\beta \text { or } \\
\text { OR }\end{array}$ & $95 \% \mathrm{Cl}$ & $P$-value & $\begin{array}{l}\text { Corrected } \\
P \text {-value }\end{array}$ & $\begin{array}{l}\beta \text { or } \\
\text { OR }\end{array}$ & $95 \% \mathrm{Cl}$ & $P$-value & $\begin{array}{l}\text { Corrected } \\
P \text {-value }\end{array}$ & $\begin{array}{l}\beta \text { or } \\
\text { OR }\end{array}$ & $95 \% \mathrm{Cl}$ & $P$-value & $\begin{array}{c}\text { Corrected } \\
P \text {-value* }\end{array}$ \\
\hline \multicolumn{13}{|l|}{ Biological } \\
\hline Child age (in months) & 1.00 & $0.99,1.01$ & 0.687 & 0.860 & 1.02 & $1.00,1.03$ & 0.063 & 0.425 & 1.03 & $1.01,1.05$ & 0.008 & 0.108 \\
\hline Child is female & 1.32 & $0.75,2.35$ & 0.338 & 0.859 & $1 \cdot 16$ & $0.60,2 \cdot 24$ & 0.652 & 0.859 & $1 \cdot 28$ & $0 \cdot 76,2 \cdot 17$ & 0.350 & 0.859 \\
\hline Woman's age (in years) & 0.99 & $0.95,1.03$ & 0.706 & 0.860 & 0.96 & $0.88,1.06$ & 0.434 & 0.859 & 0.97 & $0.92,1.03$ & 0.324 & 0.859 \\
\hline \multicolumn{13}{|l|}{ Environmental } \\
\hline Food supply shortage & 0.87 & $0.77,0.98$ & 0.024 & 0.259 & $1 \cdot 12$ & $0.89,1.42$ & 0.344 & 0.859 & $1 \cdot 20$ & $1.01,1.42$ & 0.034 & 0.278 \\
\hline Duration of residence (in years) & 1.03 & $0.99,1.07$ & 0.210 & 0.859 & 0.99 & $0.93,1.05$ & 0.640 & 0.859 & 0.98 & $0.93,1.03$ & 0.403 & 0.859 \\
\hline \multicolumn{13}{|l|}{ Behavioural } \\
\hline Woman's dietary diversity score in the past $24 \mathrm{~h}$ & 0.91 & $0.78,1.06$ & 0.230 & 0.859 & 0.94 & $0.61,1.43$ & 0.764 & 0.860 & 1.09 & $0.76,1.57$ & 0.621 & 0.859 \\
\hline Woman's minimum dietary diversity in the past $24 \mathrm{~h}$ & 0.61 & $0.38,0.97$ & 0.036 & 0.278 & 0.96 & $0.36,2.56$ & 0.930 & 0.961 & 1.36 & $0.58,3.18$ & 0.473 & 0.859 \\
\hline Man's dietary diversity score in the past $24 \mathrm{~h}$ & 0.92 & $0.82,1.02$ & 0.114 & 0.616 & 0.93 & $0.61,1.40$ & 0.720 & 0.860 & 0.99 & $0 \cdot 70,1 \cdot 10$ & 0.938 & 0.961 \\
\hline Man's minimum dietary diversity in the past $24 \mathrm{~h}$ & 0.42 & $0.25,0.73$ & 0.002 & 0.036 & 0.80 & $0.20,3.29$ & 0.758 & 0.860 & 1.04 & $0.32,3.34$ & 0.950 & 0.961 \\
\hline Child's dietary diversity score in the past $24 \mathrm{~h}$ & 0.92 & $0.74,1.06$ & 0.484 & 0.859 & 0.92 & $0.58,1.46$ & 0.720 & 0.860 & 1.02 & $0.74,1.40$ & 0.910 & 0.961 \\
\hline Child's minimum dietary diversity in the past $24 \mathrm{~h}$ & 0.62 & $0.30,1.29$ & 0.203 & 0.859 & 0.71 & $0.24,2 \cdot 11$ & 0.538 & 0.859 & $1 \cdot 10$ & $0.51,2.39$ & 0.810 & 0.893 \\
\hline \multicolumn{13}{|l|}{ Socio-economic and demographic } \\
\hline Low household wealth & $2 \cdot 21$ & $1.58,3.09$ & $<0.001$ & $<0.001$ & $1 \cdot 31$ & $0.50,3.41$ & 0.586 & 0.859 & 1.27 & $0.50,3.24$ & 0.614 & 0.859 \\
\hline High housing floor quality & 0.31 & $0.21,0.47$ & $<0.001$ & $<0.001$ & 1.53 & $0.31,7.41$ & 0.599 & 0.859 & 1.72 & $0.34,8.77$ & 0.517 & 0.859 \\
\hline Household has access to improved latrines & 0.83 & $0.55,1.26$ & 0.378 & 0.859 & 1.92 & $0.39,9.38$ & 0.421 & 0.859 & 1.74 & $0.36,8.54$ & 0.494 & 0.859 \\
\hline Household is food secure & 0.70 & $0.24,1.97$ & 0.495 & 0.859 & 0.61 & $0 \cdot 20,1 \cdot 81$ & 0.370 & 0.859 & 1.03 & $0.35,3.03$ & 0.961 & 0.961 \\
\hline Household size & 0.98 & $0.92,1.05$ & 0.568 & 0.859 & 1.03 & $0.93,1 \cdot 13$ & 0.606 & 0.859 & 0.98 & $0.86,1 \cdot 11$ & 0.750 & 0.860 \\
\hline Woman has primary education or higher & 0.81 & $0.53,1.24$ & 0.329 & 0.859 & 1.35 & $0.49,3.72$ & 0.558 & 0.859 & 1.97 & $0.85,4.58$ & 0.114 & 0.616 \\
\hline Man has primary education or higher & 0.78 & $0.48,1.27$ & 0.317 & 0.859 & 1.54 & $0.56,4.27$ & 0.403 & 0.859 & 1.75 & $0.67,4.56$ & 0.255 & 0.859 \\
\hline
\end{tabular}

${ }^{*} P$-value corrected for multiple hypothesis testing using the Benjamini-Yekutieli method to control the false discovery rate. 


\section{Nublic Health Nutrition}

Table 6 Multivariate factors associated with household-level forms of double burden of malnutrition in Kersa

\begin{tabular}{|c|c|c|c|c|c|c|c|c|c|c|c|c|}
\hline & \multicolumn{4}{|c|}{ Concurrent child overweight and stunting } & \multicolumn{4}{|c|}{ Overweight woman and stunted child } & \multicolumn{4}{|c|}{ Overweight adult and stunted child } \\
\hline & $\begin{array}{l}\beta \text { or } \\
\text { OR }\end{array}$ & $95 \% \mathrm{Cl}$ & $P$-value & $\begin{array}{c}\text { Corrected } \\
P \text {-value }\end{array}$ & $\begin{array}{l}\beta \text { or } \\
\text { OR }\end{array}$ & $95 \% \mathrm{Cl}$ & $P$-value & $\begin{array}{c}\text { Corrected } \\
P \text {-value* }\end{array}$ & $\begin{array}{l}\beta \text { or } \\
\text { OR }\end{array}$ & $95 \% \mathrm{Cl}$ & $P$-value & $\begin{array}{c}\text { Correcteo } \\
P \text {-value* }\end{array}$ \\
\hline \multicolumn{13}{|l|}{ Biological } \\
\hline Child age (in months) & 1.01 & $1.00,1.02$ & 0.219 & 0.704 & 1.02 & $1.00,1.04$ & 0.016 & 0.180 & 1.03 & $1.01,1.06$ & 0.011 & 0.165 \\
\hline Child is female & 1.47 & $0.82,2.61$ & 0.192 & 0.704 & $1 \cdot 18$ & $0.61,2.27$ & 0.627 & 0.882 & 1.24 & $0.73,2.10$ & 0.423 & 0.814 \\
\hline Woman's age (in years) & 0.98 & $0.93,1.03$ & 0.377 & 0.814 & 0.96 & $0.84,1.09$ & 0.508 & 0.882 & 0.98 & $0.92,1.03$ & 0.403 & 0.814 \\
\hline \multicolumn{13}{|l|}{ Environmental } \\
\hline Food supply shortage & 0.88 & $0.79,0.99$ & 0.030 & 0.225 & $1 \cdot 11$ & $0.90,1.36$ & 0.338 & 0.814 & $1 \cdot 15$ & $1.01,1.32$ & 0.038 & 0.244 \\
\hline Duration of residence (in years) & 1.02 & $0.96,1.09$ & 0.534 & 0.882 & 1.00 & $0.91,1.11$ & 0.947 & 0.999 & 0.99 & $0.94,1.05$ & 0.716 & 0.976 \\
\hline \multicolumn{13}{|l|}{ Behavioural } \\
\hline Woman's dietary diversity score in the past $24 \mathrm{~h}$ & 1.04 & $0.90,1.21$ & 0.580 & 0.882 & 1.01 & $0.61,1.68$ & 0.977 & 0.999 & $1 \cdot 19$ & $0.81,1.75$ & 0.372 & 0.814 \\
\hline Man's dietary diversity score in the past $24 \mathrm{~h}$ & 0.98 & $0.81,1 \cdot 18$ & 0.824 & 0.999 & 0.93 & $0.60,1.44$ & 0.749 & 0.991 & 0.89 & $0.66,1.20$ & 0.434 & 0.814 \\
\hline Child's dietary diversity score in the past $24 \mathrm{~h}$ & 1.02 & $0.83,1.25$ & 0.874 & 0.999 & 0.88 & $0.54,1.41$ & 0.585 & 0.882 & 0.91 & $0.61,1.34$ & 0.617 & 0.882 \\
\hline \multicolumn{13}{|l|}{ Socio-economic and demographic } \\
\hline Low household wealth & 1.92 & $1 \cdot 18,3 \cdot 11$ & 0.008 & 0.165 & 1.48 & $0 \cdot 69,3 \cdot 17$ & 0.311 & 0.814 & 1.74 & $0.87,3.45$ & 0.115 & 0.575 \\
\hline High housing floor quality & 0.33 & $0.20,0.53$ & $<0.001$ & $<0.001$ & 1.00 & $0.36,2 \cdot 81$ & 0.999 & 0.999 & 1.07 & $0.43,2.62$ & 0.890 & 0.999 \\
\hline Household has access to improved latrines & 2.08 & $1.07,4.04$ & 0.030 & 0.225 & 2.56 & $0.87,7.52$ & 0.088 & 0.495 & 1.81 & $0.77,4.25$ & 0.172 & 0.704 \\
\hline Household is food secure & 0.66 & $0.24,1.92$ & 0.425 & 0.814 & 0.62 & $0.23,1.65$ & 0.339 & 0.814 & 0.98 & $0.39,2.48$ & 0.965 & 0.999 \\
\hline Household size & 1.00 & $0.93,1.06$ & 0.899 & 0.999 & 1.03 & $0.97,1.09$ & 0.398 & 0.814 & 1.00 & $0.92,1.08$ & 0.955 & 0.999 \\
\hline Woman has primary education or higher & 1.00 & $0.68,1.45$ & 0.981 & 0.999 & 0.74 & $0.24,2 \cdot 24$ & 0.590 & 0.882 & 1.43 & $0.82,2.48$ & 0.205 & 0.704 \\
\hline Man has primary education or higher & 1.07 & $0.58,1.97$ & 0.840 & 0.999 & 1.91 & $0.76,4.80$ & $0 \cdot 168$ & 0.704 & 1.22 & $0.58,2.57$ & 0.598 & 0.882 \\
\hline
\end{tabular}

${ }^{\star} P$-value corrected for multiple hypothesis testing using the Benjamini-Yekutieli method to control the false discovery rate. 
longer duration of residence in the city, religion and larger household size were associated with higher odds of overweight adult and stunted child (Table 4). No factors remained significant after correction for multiple comparisons. However, in the analyses using the 7-d diet recall, higher women's dietary diversity was associated with lower odds of overweight adult and stunted child, whereas higher men's dietary diversity was associated with higher odds of this DBM form (see online Supplemental Table 2), though only the latter association remained statistically significant after correcting for multiple comparisons. In Kersa, older child age and higher number of food supply shortages were associated with increased odds of overweight adult and stunted child in univariate models, but estimates were no longer significant after correcting for multiple comparisons (Table 5). Likewise, in the multivariate model, older child age and higher number of food supply shortages remained associated with higher odds of this outcome, but only prior to adjusting for multiple comparisons (Table 6). None of these factors remained statistically significant after adjusting for multiple comparisons.

\section{Discussion}

We showed that similar forms of household-level DBM manifest in urban and rural Ethiopian households. Overweight adult and stunted child was the most prominent form of household-level DBM in Addis Ababa, followed by overweight woman and stunted child, and concurrent child overweight and stunting. Other forms of household-level DBM were virtually non-existent. In Kersa district, concurrent child overweight and stunting was most common affecting $11 \%$ of households, with other forms of household-level DBM affecting $<5 \%$ of households. The primary factors associated with household-level DBM in Addis Ababa were longer duration of residence in the city, women's employment and larger household size. In Kersa, more food supply shortages, low household wealth and improved household sanitation were factors associated with higher prevalence of household-level DBM, whereas improved housing floor quality was associated with lower prevalence.

The high prevalence of concurrent child overweight and stunting in Kersa district is of note. Several explanations are plausible. First, studies based on the developmental origin of health and disease (DOHaD) theory have shown that foetal growth restriction, low birth weight and being born small for gestational age (risk factors for childhood stunting ${ }^{(29)}$ ) are associated with increased risk of childhood overweight and obesity ${ }^{(33-35)}$. Second, child stunting is associated with impaired fat oxidation and decreased energy expenditures, both of which predispose to developing obesity ${ }^{(36,37)}$. Third, Ethiopian diets, which are primarily cereal-based, high in carbohydrates, and low in protein,
$\mathrm{Zn}$, and vitamin $\mathrm{A}^{(38)}$, could also help explain this high prevalence of concurrent child overweight and stunting. If children are receiving primarily energy-dense foods, this could help explain concurrent overweight (driven by high carbohydrate intake) and stunting (driven by low or inadequate micronutrient intake).

The household-level DBM prevalence we observed was much higher than the nationally representative Lancet estimates which showed that concurrent child overweight and stunting was the most prevalent form of household-level DBM at $2.93 \%{ }^{(4)}$. Malnutrition levels in our samples were generally similar to those for the Addis Ababa region and rural settings ${ }^{(2)}$. The somewhat higher adult overweight prevalence and lower stunting prevalence in Addis Ababa and lower adult underweight prevalence in Kersa district (relative to national estimates) can help account for the differences between the nationally representative household-level DBM estimates and ours. Importantly, these differences in household-level DBM estimates highlight large within country disparities. As expected, household-level DBM forms involving an overweight adult were more prevalent in the urban area, in agreement with evidence from SSA ${ }^{(6)}$ and Ethiopia ${ }^{(39)}$.

The low prevalence of household-level DBM in Ethiopia can at least partially be attributed to more limited factors accelerating the global nutrition transition, for example, transformation of the global retail food system, increased supply of packaged and processed foods, and global diet shifts towards increased consumption of sugar-sweetened beverages (SSB), $\mathrm{Na}$ and fats ${ }^{(4,40)}$. The prohibition of foreign direct investment in food retail has eliminated the role of multinational supermarkets and led to slower rollout of modern food retailers in the country, relative to other $\mathrm{LMIC}^{(41)}$. Although the private retail sector in Ethiopia is growing in large urban settings, modern retail shops account for only $1-3 \%$ of cereal, fruit, vegetable and processed foods sales in Addis Ababa ${ }^{(41)}$. The absence of multinational food retailers has likely slowed the spread of low-cost pre-packaged processed and ultra-processed unhealthy foods and beverages that drive the rise of DBM in other $\mathrm{LMIC}^{(4)}$. In addition, the food supply remains high in complex carbohydrates and low in sugars and unhealthy fats. The increase in palm oil and milk as fat sources may be signalling the emergence of more highly processed foods. However, these changes are not yet representative of patterns exhibited by most LMIC that have experienced major shifts in food supply towards increasing fats and decreasing carbohydrates supply ${ }^{(42)}$. Lastly, Ethiopian diets are still low in non-essential foods and beverages. Ethiopia has the lowest $\mathrm{Na}^{(43)}$ and trans fats ${ }^{(44)}$ consumption levels in the world, and lower SSB consumption than other $\mathrm{LMIC}^{(45)}$. Consumption of ultra-processed foods in Addis Ababa is also low ${ }^{(46)}$. In fact, Ethiopian diets are shifting towards high-value foods, for example, more expensive cereals, animal source foods, fruits and vegetables, and enset (a root crop known as false banana) ${ }^{(47)}$. 
All these factors together can help explain the low prevalence of household-level DBM in Ethiopia. However, many of these estimates of $\mathrm{Na}$, trans fat and SSB consumption were derived from studies conducted nearly a decade before our data were collected. It is unclear how consumption trends have changed since then and how these changes may be associated with household-level DBM.

With respect to DBM factors, the only environmental factors associated with household-level DBM were duration of residence in Addis Ababa and food supply shortages in Kersa, both of which increased the odds of overweight adult and stunted child. The former likely worked through longer exposure to a relatively more obesogenic urban environment (albeit less obesogenic than other LMIC settings), whereas the latter by reducing consumption of nutritious foods. Of note is that despite the lower number of food supply shortages in Addis Ababa, food security was less prevalent in the Addis Ababa sample relative to the Kersa sample. This may be due to higher urban food prices: Addis Ababa residents likely purchase their food, whereas Kersa residents (who are primarily farmers) produce it. More work is needed to understand why distance to market was not associated with household-level DBM. Prior work in Ethiopia has shown that greater distance to market was associated with lower food consumption, higher food insecurity and less diverse diets, but not with women's or children's anthropometric outcomes ${ }^{(48)}$. However, this work was conducted in undernourished populations. In populations where overnutrition is more prevalent, greater distance to market could help reduce DBM by increasing energy expenditure. Future studies should be specifically designed to assess other aspects of the food environment hypothesised to determine DBM, such as food availability, prices, marketing and promotion ${ }^{(49)}$.

Importantly, adult dietary diversity was positively associated with concurrent child overweight and stunting in Kersa district, though only in univariate analyses. Women's dietary diversity was an associated factor regardless of the recall period (both $24 \mathrm{~h}$ and $7 \mathrm{~d}$ ), whereas men's dietary diversity was an associated factor only in the primary analyses using a 24-h recall period. Although no other studies have documented the role of diet in household-level DBM in Ethiopia or SSA, our findings are generally in agreement with results from both high- and low-income settings indicating diverse diets rich in vitamin A-rich fruits and vegetables and animal source foods are protective of stunting and can reduce the burden of diet-related disease ${ }^{(49)}$, including obesity. The homogenous household diets in Kersa imply that as adults increase their dietary diversity so do their children, which protects them from concurrent overweight and stunting. In contrast, men's dietary diversity was an associated factor for overweight woman/adult and stunted child in Addis Ababa, but only using a 7-d recall period. Several explanations for this association are plausible. Men might be allocated more nutritious foods within the household given their higher economic contribution (only $34 \%$ of women in Addis Ababa were employed). They might purchase and consume more nutritious foods outside the home, reducing household food budget and thus increasing malnutrition risk among other household members. Alternatively, a more diversified diet may be higher in energy and micronutrients ${ }^{(50)}$, which could translate into higher likelihood of adult overweight. Of note is that we lacked data on intrahousehold food distribution, out-of-home food consumption, and not all men we interviewed were biological fathers of the children or the husband/partner of the woman. Thus, we can only speculate on the exact mechanisms through which adult diet may help reduce the odds of concurrent child overweight and stunting. Moreover, the men's dietary diversity indicator we used has not been validated for use among men and it might not adequately capture micronutrient intake. Future research should carefully assess the role of men's diet in household-level DBM.

Our results should be interpreted with several other caveats. First, the diet assessment did not collect information on portion size, frequency of food consumption or out-of-home food consumption, all of which contribute to excess adiposity. The dietary diversity indicators we used are designed to assess maternal and child health and have not been validated against non-communicable disease risk ${ }^{(51)}$. Their cultural appropriateness in Ethiopia has not been assessed either. Moreover, DDS and MDD have only been validated among Burkinabe children of 24-59 months of age ${ }^{(28)}$, and more work is needed to assess the validity of these measures in children of 24-59 months of age in other settings. Second, our surveys were not explicitly designed to study DBM. We lacked data on other indicators used in household-level DBM definitions (e.g. anaemia, micronutrient deficiencies, diabetes ${ }^{(3)}$, hypertension and dyslipidaemia), and other factors associated with DBM (e.g. early-life experiences, urban and built environment, physical activity $\left.{ }^{(12)}\right)$. Thus, we may be underestimating the burden of malnutrition in all its forms. Factors such as physical activity may be particularly relevant in urban settings, typically characterised by high availability of cheap, energy-dense foods and reduced occupational physical activity and active transport ${ }^{(52)}$. Third, our sample in Kersa district included both rural and urban kebeles. Although the entire district is considered rural, the urban kebeles are small towns with permanent electricity supply and it is possible that they differ from rural kebeles in ways that might be important for DBM. In addition, including these urban kebeles may limit the generalisability of our findings to other rural areas. Fourth, data were collected in different periods in the year: the dry season in Addis Ababa and the rainy season in Kersa district. Although adult and child diets appeared similar in our samples, it is possible that this seasonality influenced other DBM factors which we did not account for in our analyses. Finally, any analysis aiming to understand all the factors associated with household-level DBM will suffer from a problem of multiplicity. To address this issue, 
we presented both standard $P$-values and $P$-values corrected for multiple comparisons. However, by applying this correction, we inevitably increase the risk of type II error (false-negatives). Our selection of factors was based on the WHO framework on the drivers of $\mathrm{DBM}^{(12)}$, and we therefore can be confident that all factors included in our models are theoretically important. However, due to this problem of multiplicity, our small sample size, the low prevalence of some associated factors and the low prevalence of household-level DBM, we were unable to determine the direction and magnitude of the associations in our samples with sufficient statistical certainty. These statistical issues are evidenced by the opposing associations between DBM, low household wealth, improved household sanitation and improved housing floor. Although significantly negatively correlated, low household wealth and improved household sanitation were both associated with increased risk of concurrent child stunting and overweight in Kersa.

Nevertheless, our findings have implications for interventions to address both undernutrition and overnutrition. Despite the low household-level DBM prevalence, the co-occurrence of undernutrition and overweight at the population level remains a problem as evidenced by the high prevalence of women's overweight in Addis Ababa (37.2\%), high prevalence of child stunting in both Addis Ababa and Kersa (18.6\% and 56.6\%, respectively), and high prevalence of child underweight and wasting in Kersa (33.5\% and 19\%, respectively) we observed. Examining the associated factors with population-level undernutrition and overweight was beyond the scope of this article, since multiple prior studies have assessed the national prevalence and associated factors of population-level DBM in Ethiopia ${ }^{(7-11)}$. However, given the high population-level prevalence of both forms of malnutrition, double-duty actions, that is, actions which simultaneously address multiple forms of malnutrition ${ }^{(53)}$, should be targeted at the population level to help alleviate the larger population-level burden of malnutrition. Further, our findings indicate that double-duty interventions should target women and children given the higher (albeit generally low) prevalence of household-level DBM involving these individuals. Several successful double-duty interventions $^{(49)}$ can help Ethiopia address DBM: breast-feeding promotion, complementary feeding education, social safety nets, nutrition-sensitive agriculture and food policy. Social and behaviour change communication (SBCC) programmes which have been shown to increased exclusive breast-feeding rates ${ }^{(54)}$ should also include messaging to reduce maternal obesity and micronutrient deficiencies, which alter the biology of lactation ${ }^{(13)}$. Breast-feeding and complementary feeding education can also be included in the SBCC strategy of the Productive Safety Net Programme (PSNP). This safety net programme can further be leveraged to address DBM by redesigning the food transfer (e.g. to provide nutritious foods or earmark it for women and young children) and/or including messages on nutritious and healthy diets for the whole family. Likewise, the national homestead gardening programme already includes a SBCC strategy promoting breast-feeding and complementary feeding practices. Improving the take up (currently as low as $7.5 \%$ of target households in some areas $^{(55)}$ ) can also serve to address DBM through the SBCC strategy but also through the direct production of healthy and nutritious foods. Lastly, additional policy changes can help support DBM prevention efforts. Specifically, the elimination of promotion of breast-feeding substitutes and formula is paramount to bolster breastfeeding promotion efforts ${ }^{(49,56,57)}$.

\section{Conclusion}

We showed that concurrent child overweight and stunting, and overweight woman or adult and stunted child were the most prevalent forms of household-level DBM among urban and rural Ethiopian households. Environmental, socio-economic and demographic factors emerged as the most prominent factors associated with these DBM forms. Despite the low household-level DBM prevalence we observed, there was a high burden of child undernutrition and maternal overweight at the population level. Interventions to address DBM should focus on women and young children at the population level, who experienced the highest burden. Promising double-duty actions include breast-feeding promotion, complementary feeding education, redesigning the food transfer of the national safety net programme, improving take up of the national homestead gardening programme and food policy interventions. Ethiopia has already demonstrated strong political commitment towards reducing all forms of malnutrition, which features prominently in the country's strategic policies and plans. The National Nutrition Programme already outlines ways and initiatives to improve multisectoral coordination and implementation capacity ${ }^{(58)}$, indicating that the political commitment and logistical, financial and implementation capacity for these double-duty interventions exists. Moving forward, DBM targets and double-duty initiatives should be explicitly included in national nutrition policies and programmes to help Ethiopia eliminate all forms malnutrition at the household and population level.

\section{Acknowledgements}

Acknowledgements: The authors would like to acknowledge the study participants and data collectors for their time and for making the study possible. Financial support: The Addis Ababa study was funded by the United Kingdom Economic and Social Research Council (ESRC) 
and Department for International Development (DFID) Joint Fund for Poverty Alleviation Research (grant number: ES/R002118/1). The Kersa study was funded by Harvard T.H. Chan School of Public Health Office for Research Strategy and Development (grant number: not applicable). The funders had no role in study design, data collection and analysis, decision to publish, or preparation of the manuscript. Conflicts of interest: There are no conflicts of interest. Authorship: L.B. conceptualised the analyses presented in this paper. Y.B., A.W.T., G.D., C.R.C. and W.W.F. designed and implemented the Addis Ababa study. A.W.T. and Y.B. led the Addis Ababa data collection activities. N.A. and W.W.F. designed the Kersa study, and N.A., E.C.H. and W.W.F. implemented it. N.A. led the Kersa data collection activities. L.B. led the data analyses and drafted the manuscript. All authors critically reviewed the manuscript, contributed to the intellectual content and approved the final manuscript. L.B. had final responsibility for submitting this article for publication. Ethics of human subject participation: Written informed consent was obtained by fieldworkers who provided information about the study to each participant. The Addis Ababa study received ethical approved by the institutional review boards of the Addis Continental Institute of Public Health (reference number ACIPH/IRB/001/2018) and the Harvard T.H. Chan School of Public Health (reference number: IRB17-1825). The Kersa study received ethical approval by the Institutional Health Research Ethical Review Board of the College of Health and Medical Sciences at Haramaya University (reference number: SHE/SIM/144/708/19) and by the institutional review board of the Harvard T.H. Chan School of Public Health (reference number: IRB19-0029).

\section{Supplementary material}

For supplementary material accompanying this paper visit https://doi.org/10.1017/S1368980021003700

\section{References}

1. Institute for Health Metrics and Evaluation (IHME) (2020) GBD Compare Data Visualization. Seattle, WA: IHME, University of Washington. http://vizhub.healthdata.org/ gbd-compare (accessed September 2019).

2. Central Statistical Agency (CSA) \& ICF (2016) Ethiopia Demographic and Health Survey 2016. Addis Ababa, Ethiopia; and Rockville, MD, USA: CSA and ICF.

3. Davis JN, Oaks BM \& Engle-Stone R (2020) The double burden of malnutrition: a systematic review of operational definitions. Curr Dev Nutr 4, nzaa127.

4. Popkin BM, Corvalan C \& Grummer-Strawn LM (2020) Dynamics of the double burden of malnutrition and the changing nutrition reality. Lancet 395, 65-74.

5. Bixby H, Bentham J, Zhou B et al. (2019) Rising rural bodymass index is the main driver of the global obesity epidemic in adults. Nature 569, 260-264.
6. Jones AD, Acharya Y \& Galway LP (2016) Urbanicity gradients are associated with the household- and individual-level double burden of malnutrition in Sub-Saharan Africa. J Nutr 146, 1257-1267.

7. Yeshaw Y, Kebede SA, Liyew AM et al. (2020) Determinants of overweight/obesity among reproductive age group women in Ethiopia: multilevel analysis of Ethiopian demographic and health survey. BMJ Open 10, e034963.

8. Tebekaw Y, Teller C \& Colón-Ramos U (2014) The burden of underweight and overweight among women in Addis Ababa, Ethiopia. BMC Public Health 14, 1126.

9. Tareke AA \& Abate MG (2020) Nutritional paradox in Ethiopian women: multilevel multinomial analysis. Clin Nutr ESPEN 36, 60-68.

10. Berhane HY, Jirström M, Abdelmenan S et al. (2020) Social stratification, diet diversity and malnutrition among preschoolers: a survey of Addis Ababa, Ethiopia. Nutrients 12, 712 .

11. Gutema BT, Chuka A, Kondale M et al. (2020) The burden of malnutrition among adults residing in Arba Minch health and demographic surveillance site (HDSS): a WHO STEPS survey. J Nutr Metab 2020, 1-9.

12. World Health Organization (2017) The Double Burden of Malnutrition: Policy Brief. Geneva, Switzerland: World Health Organization.

13. Wells JC, Sawaya AL, Wibaek R et al. (2019) The double burden of malnutrition: aetiological pathways and consequences for health. Lancet 6736, 1-14.

14. Farah AM, Nour TY, Endris BS et al. (2021) Concurrence of stunting and overweight/obesity among children: evidence from Ethiopia. PLoS One 16, e0245456.

15. Keino S, Plasqui G, Ettyang G et al. (2014) Determinants of stunting and overweight among young children and adolescents in Sub-Saharan Africa. Food Nutr Bull 35, 167-178.

16. Dembélé B, Sossa Jérôme C, Saizonou J et al. (2018) Coexistence du surpoids ou obésité et retard de croissance dans les ménages du Sud-Ouest Bénin (Coexistence of overweight or obesity and stunting in households in South-West Benin). Sante Publique 30, 115.

17. Senbanjo IO, Senbanjo CO, Afolabi WA et al. (2019) Co-existence of maternal overweight and obesity with childhood undernutrition in rural and urban communities of Lagos State, Nigeria. Acta Biomed 90, 266-274.

18. Bouzitou GDN, Fayomi B \& Delisle H (2005) Child malnutrition and maternal overweight in same households in poor urban areas of Benin. Sante 15, 263-270.

19. Assefa N, Oljira L, Baraki N et al. (2016) HDSS profile: the Kersa health and demographic surveillance system. Int J Epidemiol 45, 94-101.

20. Zack RM, Irema K, Kazonda P et al. (2018) Validity of an FFQ to measure nutrient and food intakes in Tanzania. Public Health Nutr 21, 1-10.

21. World Health Organization (2000) Obesity: preventing and managing the global epidemic. Report of a WHO consultation. World Health Organ Tech Rep Ser 894, 1-253.

22. World Health Organization (2006) The WHO Child Growth Standards. Geneva, Switzerland: World Health Organization.

23. Zellelew TB (2014) Meat abstinence and its positive environmental effect: examining the fasting etiquettes of the Ethiopian Orthodox Church. Crit Res Relig 2, 134-146.

24. Schlesinger S, Neuenschwander M, Schwedhelm C et al. (2019) Food groups and risk of overweight, obesity, and weight gain: a systematic review and doseresponse meta-analysis of prospective studies. Adv Nutr 10, 205-218.

25. Martin-Prevel Y, Arimond M, Allemand P et al. (2017) Development of a dichotomous indicator for populationlevel assessment of dietary diversity in women of reproductive age. Curr Dev Nutr 1, e001701. 
26. FAO \& FHI 360 (2016) Minimum Dietary Diversity for Women: A Guide to Measurement. Rome: FAO.

27. World Health Organization, UNICEF, USAID et al. (2010) Indicators for Assessing Infant and Young Child Feeding Practices: Part 2 Measurement. Geneva: World Health Organization.

28. Diop L, Becquey E, Turowska Z et al. (2021) Standard minimum dietary diversity indicators for women or infants and young children are good predictors of adequate micronutrient intakes in 24-59-month-old children and their nonpregnant nonbreastfeeding mothers in rural Burkina Faso. J Nutr 151, 412-422.

29. Danaei G, Andrews KG, Sudfeld CR et al. (2016) Risk factors for childhood stunting in 137 developing countries: a comparative risk assessment analysis at global, regional, and country levels. PLoS Med 13, e1002164.

30. Coates J, Swindale A \& Bilinsky P (2007) Housebold Food Insecurity Access Scale (HFIAS) for Measurement of Food Access: Indicator Guide (V. 3). Washington, DC: FHI 360, FANTA.

31. Benjamini Y \& Yekutieli D (2001) The control of the false discovery rate in multiple testing under dependency. Ann Stat 29, 1165-1188.

32. StataCorp. LP (2019) Stata Statistical Software: Release 16. College Station, TX: StataCorp. LP.

33. Barouki R, Gluckman PD, Grandjean P et al. (2012) Developmental origins of non-communicable disease: implications for research and public health. Environ Health 11, 42.

34. Oken E \& Gillman MW (2003) Fetal origins of obesity. Obes Res 11, 496-506.

35. Hoffman DJ, Reynolds RM \& Hardy DB (2017) Developmental origins of health and disease: current knowledge and potential mechanisms. Nutr Rev 75, 951-970.

36. Hoffman DJ, Sawaya AL, Verreschi I et al. (2000) Why are nutritionally stunted children at increased risk of obesity? Studies of metabolic rate and fat oxidation in shantytown children from São Paulo, Brazil. Am J Clin Nutr 72, 702-707.

37. Sawaya AL \& Roberts S (2003) Stunting and future risk of obesity: principal physiological mechanisms. Cad Saude Publica 19, S21-S28.

38. Ethiopian Public Health Institute (2013) Ethiopia National Food Consumption Survey. Addis Ababa, Ethiopia: Ethiopian Public Health Institute.

39. Dagnew GW \& Asresie MB (2021) Comparative assessment of overweight/obesity among rural and urban reproductiveage women in Ethiopia: evidence from a cross-sectional 2016 national survey. Nutr Health 27, 221-230.

40. Popkin BM (2017) Relationship between shifts in food system dynamics and acceleration of the global nutrition transition. Nutr Rev 75, 73-82.

41. Assefa T, Abebe G, Lamoot I et al. (2016) Urban food retailing and food prices in Africa: the case of Addis Ababa, Ethiopia. J Agribus Dev Emerg Econ 6, 90-109.

42. Sheehy T, Carey E, Sharma S et al. (2019) Trends in energy and nutrient supply in Ethiopia: a perspective from FAO food balance sheets. Nutr J 18, 46.
43. Powles J, Fahimi S, Micha R et al. (2013) Global, regional and national sodium intakes in 1990 and 2010: a systematic analysis of $24 \mathrm{~h}$ urinary sodium excretion and dietary surveys worldwide. BMJ Open 3, e003733.

44. Micha R, Khatibzadeh S, Shi P et al. (2014) Global, regional, and national consumption levels of dietary fats and oils in 1990 and 2010: a systematic analysis including 266 countryspecific nutrition surveys. BMJ 348, g2272.

45. Singh GM, Micha R, Khatibzadeh S et al. (2015) Global, regional, and national consumption of sugar-sweetened beverages, fruit juices, and milk: a systematic assessment of beverage intake in 187 countries. PLoS One 10, $\mathrm{e} 0124845$.

46. Melesse MB, van den Berg M, de Brauw A et al. (2019) Understanding Urban Consumers' Food Choice Behavior in Ethiopia: Promoting Demand for Healthy Foods. Washington, DC; and Addis Ababa, Ethiopia: International Food Policy Research Institute (IFPRI) and Ethiopian Development Research Institute (EDRI).

47. Worku IH, Dereje M, Minten B et al. (2017) Diet transformation in Africa: the case of Ethiopia. Agric Econ 48, 73-86.

48. Stifel D \& Minten B (2017) Market access, well-being, and nutrition: evidence from Ethiopia. World Dev 90, 229-241.

49. Hawkes C, Ruel MT, Salm L et al. (2019) Double-duty actions: seizing programme and policy opportunities to address malnutrition in all its forms. Lancet 395, 142-155.

50. Ponce X, Ramirez E \& Delisle H (2006) A more diversified diet among mexican men may also be more atherogenic. $J$ Nutr 136, 2921-2927.

51. Miller V, Webb P, Micha R et al. (2020) Defining diet quality: a synthesis of dietary quality metrics and their validity for the double burden of malnutrition. Lancet Planet Health 4, e352-e370.

52. Ford ND, Patel SA \& Narayan KMV (2017) Obesity in low- and middle-income countries: burden, drivers, and emerging challenges. Annu Rev Public Health 38, 145-164.

53. Hawkes C, Ruel M, Wells JC et al. (2020) The double burden of malnutrition - further perspective - authors' reply. Lancet 396, 815-816.

54. Kim SS, Rawat R, Mwangi EM et al. (2016) Exposure to largescale social and behavior change communication interventions is associated with improvements in infant and young child feeding practices in Ethiopia. PLoS One 11, 1-18.

55. Hirvonen K \& Headey D (2018) Can governments promote homestead gardening at scale? Evidence from Ethiopia. Glob Food Sec 19, 40-47.

56. Jaacks LM, Kavle J, Perry A et al. (2017) Programming maternal and child overweight and obesity in the context of undernutrition: current evidence and key considerations for low- and middle-income countries. Public Health Nutr 20, 1286-1296.

57. World Health Organization (2017) Double-Duty Actions for Nutrition. Geneva, Switzerland: World Health Organization.

58. GFDRE (2016) National Nutrition Programme 2016-2020. Addis Ababa: Government of the Federal Democratic Republic of Ethiopia (GFDRE). 